\title{
Comorbidity of respiratory and cardiovascular diseases among the elderly residing close to mine dumps in South Africa: A cross-sectional study
}

\author{
V Nkosi, MPH; J Wichmann, PhD; K Voyi, PhD \\ School of Health Systems and Public Health, Faculty of Health Sciences, University of Pretoria, South Africa
}

Corresponding author: V Nkosi (vnkosi334@gmail.com)

Background. Pollution arising from mine dumps in South Africa (SA) has been a source of concern to nearby communities.

Objective. To investigate whether comorbidity of respiratory and cardiovascular diseases among elderly persons ( $\geq 55$ years) was associated with proximity to mine dumps.

Methods. Elderly persons in communities $1-2 \mathrm{~km}$ (exposed) and $\geq 5 \mathrm{~km}$ (unexposed) from five preselected mine dumps in Gauteng and North West provinces in SA were included in a cross-sectional study.

Results. Exposed elderly persons had a significantly higher prevalence of cardiovascular and respiratory diseases than those who were unexposed. Multiple logistic regression analysis indicated that living close to mine dumps was significantly associated with asthma + hypertension (odds ratio (OR) 1.67; 95\% confidence interval (CI) 1.22 - 2.28), asthma + pneumonia (OR 1.86; 95\% CI 1.14 - 3.04), emphysema + arrhythmia (OR 1.38; 95\% CI 1.07 - 1.77), emphysema + myocardial infarction (OR 2.01; 95\% CI 1.73 - 2.54), emphysema + pneumonia (OR 3.36; 95\% CI 1.41 - 7.98), hypertension + myocardial infarction (OR 1.60; 95\% CI 1.04 - 2.44) and hypertension + pneumonia (OR 1.34; 95\% CI 1.05 - 1.93).

Conclusion. Detrimental associations between comorbidity of the health outcomes and proximity to mine dumps were observed among the elderly in SA.

S Afr Med J 2016;106(3):290-297. DOI:10.7196/SAMJ.2016.v106i3.10243

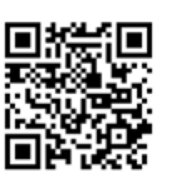

Pollution arising from mine dumps that serve as depositories for waste materials produced during goldmining processes, has been a source of concern to communities located in close proximity in South Africa (SA) ${ }^{[1,2]}$ The crushed sand-like refuse material is generated during extraction and milling of ground ore during the mining process. ${ }^{[3,4]}$ The material contains a complex mixture of heavy metals and trace elements such as gold, copper, lead, zinc, arsenic, cadmium and selenium. ${ }^{[2,3,5]}$ Mine dumps are generally located in low-lying areas near mining sites, and dust particles or particulate matter are transported to nearby communities by air or by soil and water contamination. ${ }^{[3]}$ The major routes of entry to the body upon exposure include contact with skin or eyes, inhalation and ingestion. Exposed communities tend to be historically marginalised ethnic groups of low socioeconomic status and living in government-funded houses, informal settlements and retirement homes, ${ }^{[8]}$ and are often elderly persons and children. ${ }^{[2,6,7]}$ Moreover, some of the exposed communities also live near highways where there is heavy traffic flow and industries, so are exposed to the effects of ambient particulate matter air pollution, resulting in an increased risk of developing respiratory and cardiovascular diseases. ${ }^{[9-14]}$ Elderly people are potentially highly susceptible to the effects of ambient air pollution as a result of normal and pathological ageing. ${ }^{[15]} \mathrm{An}$ increased prevalence of respiratory disease was observed in people living near mining sites in both SA and Portugal, compared with a control group living further away. ${ }^{[6,7,16]}$

No studies have investigated whether exposure to mine dust or living in close proximity to mine dumps poses an increased risk for comorbidity of respiratory and cardiovascular diseases among elderly people, and none have investigated the effects between combinations of various air pollution sources, including mine dust.

Comorbidity was defined in the present study as having more than one respiratory or cardiovascular disease. One possible reason for the overlap between these two diseases is that they share the same risk factors, which may cause or exacerbate respiratory or cardiovascular diseases in vulnerable individuals. ${ }^{[17]}$

This study is part of a larger project initiated by the Mine Health Safety Council of South Africa (MHSC) around communities located near mine dumps in Gauteng and North West provinces. No studies have investigated the association between potential risk factors and the comorbidity of respiratory and cardiovascular diseases among elderly people living near mine dumps in SA.

\section{Objective}

To investigate whether comorbidity of respiratory and cardiovascular diseases among the elderly was associated with proximity to mine dumps. Effect modification between proximity to mine dumps and other air pollution sources was also investigated, e.g. the type of fuel used for cooking/heating in the home, tobacco smoking, and a history of occupational exposure to dust or chemical fumes.

\section{Methods}

The study methods have been described in detail elsewhere and a summary of the methods has been provided. ${ }^{[6]}$ Ethical approval (ref. no. 235/2011) was obtained from the Research Ethics Committee, Faculty of Health Sciences, University of Pretoria. Verbal and written consent was obtained from the participants before commencement of interviews.

\section{Population and study design}

A cross-sectional study of 2397 elderly ( $\geq 55$ years) people from communities living $1-2 \mathrm{~km}$ (exposed) and $\geq 5 \mathrm{~km}$ (unexposed) from five preselected mine dumps in Gauteng and North West provinces was conducted during November and December 2012. Table 1 lists the selected communities, and Table 2 the population 
size of the elderly people and the targeted sample size in each community under study. The mine dumps were selected before the study by the MHSC because of large population densities around these dumps. Eleven communities were included in the study. A previously validated ATS-DLD-78 questionnaire from the British Medical Research Council was used for face-to-face interviews. ${ }^{[18]}$ The study focused on elderly people who had been living in the study communities for $\geq 5$ years. A 'knock on the door' approach was used to recruit study participants. In each community, streets were randomly selected and then four to five houses were randomly selected in each street. The sample size of each community was calculated using Epi Info version 7, with a total sample size of 3069. Population sizes were based on the 2001 census from Statistics South Africa, because the results of census 2011 were not released when the study commenced.

\section{Questionnaire administration}

Twenty-two locally trained fieldworkers were employed, with two assigned to each community. Each fieldworker received thorough training in conducting the interviews using the respiratory health questionnaire before the start of the survey. The interviews were mainly in English and were translated into the local language if the respondent did not understand the questions. The questionnaire included sections on demography, medical history, type of fuel use for residential cooking/heating, tobacco smoking habits, and history of occupational exposure to dust or chemical fumes. The outcomes of interest, e.g. arrhythmia, asthma, emphysema, hypertension, myocardial infarction and pneumonia, were based on positive answers indicating diagnosis of the conditions by a doctor. The main exposure factor of interest in this study was the distance between the study population and the mine dump. For quality control of the interviews, fieldworkers randomly selected $10 \%$ of the homes and readministered the same questionnaire to the same previously interviewed respondents to verify their responses. This verification was done 15 - 20 days after the first interview. Within the interviews, a $>10 \%$ deviation was deemed unacceptable.

\section{Statistical analysis}

Two technicians entered the collected questionnaire data into a database set up in Epi Info version 3.5.3. Data were analysed using Stata version 12. Prevalence of the health outcome, the proportion of air pollution sources under investigation, and confounding variables were calculated by dividing the number of participants who responded affirmatively by the number of questionnaires completed. Each question therefore had a different sample size. Observations marked as 'do not know', 'not stated' or 'other responses' were set as missing, but were included in the descriptive analyses. Only two explanatory variables, age and main type of fuel used for heating and cooking in the home, had missing observations. Responses to the number of cigarettes smoked per day were very low and were not included in the analysis. Pearson's $\chi^{2}$ test was applied to determine the relationship between community (exposed/ unexposed) and confounding variables. Using univariate and multiple logistic regression analysis (LRA) to estimate the likelihood of having asthma, chronic bronchitis, chronic cough, emphysema, pneumonia and wheeze, crude and adjusted odds ratios (ORs) and $95 \%$ confidence intervals (CIs) were calculated. Missing values were automatically excluded in each LRA model, so each multiple LRA model had a different sample size. To obtain adjusted ORs for the effect of 'community (exposed/unexposed)', outcomes were placed in an initial LRA model. This was followed by the addition of a potential confounder in a stepwise manner, starting with the most statistically
Table 1. Eleven communities selected in the study located in Gauteng and North West provinces, SA, during November December 2012

\begin{tabular}{|c|c|c|c|}
\hline Mine dump facility & Province & Exposed & Unexposed \\
\hline $\begin{array}{l}\text { Durban Roodepoort } \\
\text { Deep }\end{array}$ & Gauteng & Braamfischerville & Dobsonville \\
\hline $\begin{array}{l}\text { Crown Gold } \\
\text { Recoveries }\end{array}$ & Gauteng & $\begin{array}{l}\text { Diepkloof, } \\
\text { Riverlea and } \\
\text { Noordgesig }\end{array}$ & $\begin{array}{l}\text { Orlando } \\
\text { East }\end{array}$ \\
\hline $\begin{array}{l}\text { East Rand } \\
\text { Proprietary Mines }\end{array}$ & Gauteng & Reiger Park & $\begin{array}{l}\text { Windmill } \\
\text { Park }\end{array}$ \\
\hline Ergo & Gauteng & Geluksdal & $\begin{array}{l}\text { Windmill } \\
\text { Park }\end{array}$ \\
\hline Anglo Gold Ashanti & North West & Stilfontein & Jouberton \\
\hline
\end{tabular}

Table 2. Population sizes of elderly ( $\geq 55$ years) people in the 11 communities under study

\begin{tabular}{lll}
\hline Location & Population size, $\boldsymbol{N}$ & Sample size, $\boldsymbol{n}$ \\
\hline Geluksdal & 430 & 197 \\
Windmill Park & 371 & 184 \\
Reiger Park & 155 & 109 \\
Diepkloof & 10789 & 351 \\
Dobsonville & 4629 & 337 \\
Noordgesig & 668 & 235 \\
Orlando East & 5702 & 334 \\
Jouberton & 8202 & 348 \\
Stilfontein & 2974 & 324 \\
Riverlea & 1709 & 299 \\
Braamfischerville & 10789 & 351
\end{tabular}

significant from the univariate analysis. Each time a new potential confounder was added to the model, if the effect estimate between the exposure of interest and comorbidity outcome already in the models changed by more than $5.0 \%$, the additional variable was retained in the final multiple LRA; otherwise, the variable was removed and a different one was added. ${ }^{[19]}$ The most parsimonious multiple LRA models were reported, i.e. those with variables having a $p$-value of $<0.05 .{ }^{[20]}$ Community (exposed/unexposed) was considered as the main exposure factor and was therefore included in all models for each outcome of interest, regardless of whether it was statistically significant in the univariate analyses.

Effect modification between community (exposed/unexposed) and other air pollution source variables (smoking habits, occupational exposure history to dust/chemical fumes, and residential cooking/ heating fuel type) was investigated by including a multiplicative term in the model.

\section{Results}

\section{Demographic characteristics and air pollution} variables by type of community

Detailed demographic characteristics of the respondents and air pollution variables by community type have been published previously (Table 3) ${ }^{[6]}$ There were 1499 study participants from exposed and 898 from unexposed communities. 


\section{Prevalence of comorbidity stratified by type of community}

The prevalences of asthma + emphysema (1.7\%), asthma + hypertension (12.6\%), asthma + pneumonia (5.0\%), emphysema + myocardial infarction $(0.8 \%)$, emphysema + pneumonia $(2.5 \%)$, hypertension + myocardial infarction (6.5\%), hypertension + pneumonia (11.9\%) and pneumonia + arrthymia (1.9\%) in the exposed communities were higher than those in the unexposed

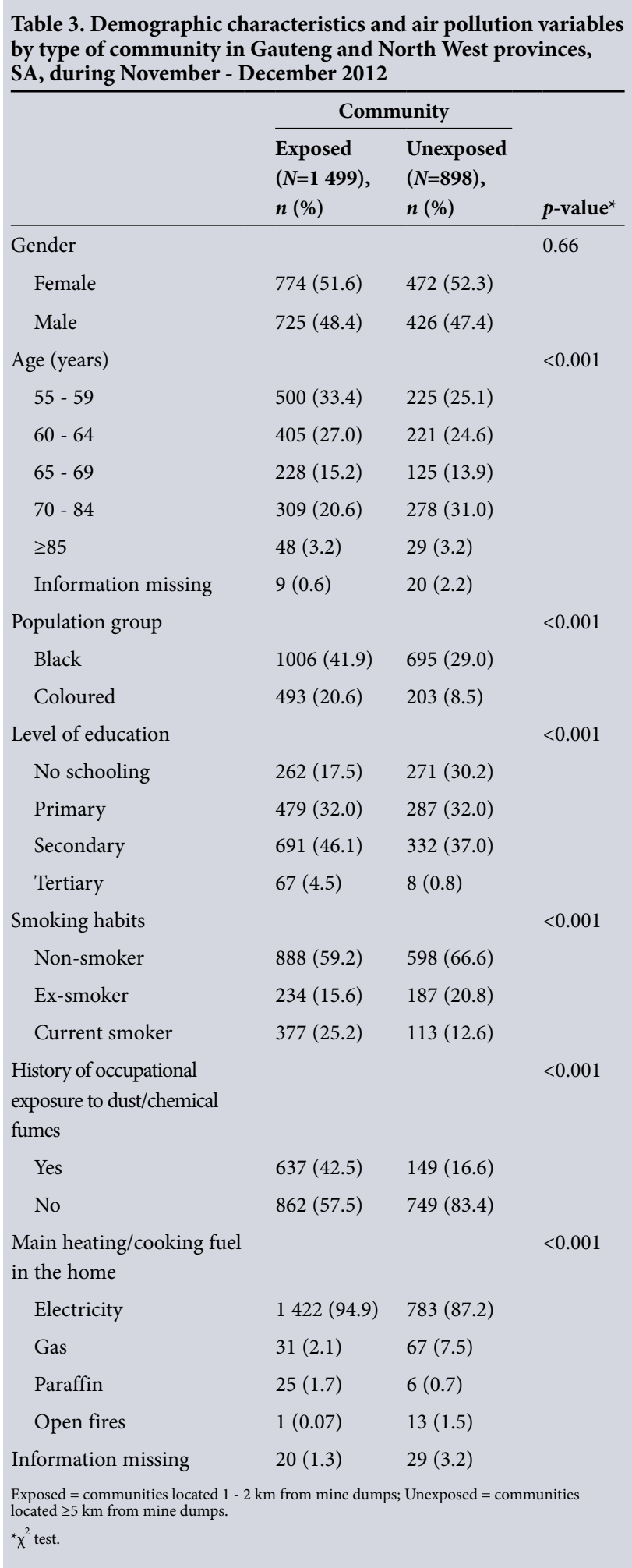

communities, where the percentages were $1.1 \%, 8.0 \%, 4.3 \%, 0.7 \%$, $0.8 \%, 4.1 \%, 8.9 \%$ and $1.8 \%$, respectively (Table 4 ).

Table 4. Prevalences of comorbidity by type of community in Gauteng and North West provinces, SA, during November December 2012

\begin{tabular}{|c|c|c|c|}
\hline & \multicolumn{2}{|c|}{ Community } & \multirow[b]{2}{*}{$\begin{array}{l}\text { Total, } \\
n(\%)\end{array}$} \\
\hline & $\begin{array}{l}\text { Exposed, } \\
n(\%)\end{array}$ & $\begin{array}{l}\text { Unexposed, } \\
n(\%)\end{array}$ & \\
\hline \multicolumn{4}{|l|}{ Asthma + arrhythmia } \\
\hline Yes & $66(4.4)$ & $44(4.9)$ & $110(4.6)$ \\
\hline No & $1432(95.5)$ & $836(93.1)$ & $2268(94.6)$ \\
\hline Missing information & $1(0.1)$ & $18(2.0)$ & $19(0.8)$ \\
\hline Total & $1499(62.5)$ & 898 (37.5) & $2397(100.0)$ \\
\hline \multicolumn{4}{|l|}{ Asthma + emphysema } \\
\hline Yes & $26(1.7)$ & $10(1.1)$ & $36(1.5)$ \\
\hline No & $1473(98.3)$ & 888 (98.9) & $2361(98.5)$ \\
\hline Missing information & - & - & - \\
\hline Total & $1499(62.5)$ & $898(37.5)$ & $2397(100.0)$ \\
\hline \multicolumn{4}{|l|}{ Asthma + hypertension } \\
\hline Yes & $189(12.6)$ & $72(8.0)$ & $261(10.9)$ \\
\hline No & $\begin{array}{l}1292 \\
(86.19)\end{array}$ & $797(88.6)$ & $2089(87.1)$ \\
\hline Missing information & $18(1.2)$ & $29(3.2)$ & $47(2.0)$ \\
\hline Total & $1499(64.1)$ & $898(37.5)$ & $2397(100.0)$ \\
\hline \multicolumn{4}{|l|}{ Asthma + pneumonia } \\
\hline Yes & $75(5.0)$ & $28(3.1)$ & $103(4.3)$ \\
\hline No & $1421(94.8)$ & $853(95.0)$ & 2274 (94.9) \\
\hline Missing information & $3(0.2)$ & $17(1.9)$ & $20(0.8)$ \\
\hline Total & $1499(64.1)$ & 898 (37.5) & $2397(100.0)$ \\
\hline \multicolumn{4}{|l|}{$\begin{array}{l}\text { Emphysema + } \\
\text { arrhythmia }\end{array}$} \\
\hline Yes & $31(2.1)$ & $20(2.2)$ & $51(2.1)$ \\
\hline No & $1468(97.9)$ & $878(97.8)$ & 2346 (97.9) \\
\hline Missing information & - & - & - \\
\hline Total & $1499(64.1)$ & 898 (37.5) & $2397(100.0)$ \\
\hline \multicolumn{4}{|l|}{$\begin{array}{l}\text { Emphysema }+ \\
\text { myocardial infarction }\end{array}$} \\
\hline Yes & $12(0.8)$ & $7(0.7)$ & $19(0.8)$ \\
\hline No & $1487(99.2)$ & $891(99.3)$ & $2378(99.2)$ \\
\hline Missing information & - & - & - \\
\hline Total & $1499(64.1)$ & $898(37.5)$ & $2397(100.0)$ \\
\hline \multicolumn{4}{|l|}{$\begin{array}{l}\text { Emphysema }+ \\
\text { pneumonia }\end{array}$} \\
\hline Yes & $38(2.5)$ & $7(0.8)$ & $45(1.9)$ \\
\hline No & $1461(97.46)$ & $891(99.2)$ & $2352(98.1)$ \\
\hline Missing information & - & - & - \\
\hline \multirow[t]{2}{*}{ Total } & 1499 (64.1) & 898 (37.5) & $2397(100.0)$ \\
\hline & & & Continued ... \\
\hline
\end{tabular}


Table 4. (continued) Prevalences of comorbidity by type of community in Gauteng and North West provinces, SA, during November - December 2012

\begin{tabular}{llll}
\hline & \multicolumn{2}{c}{ Community } & \\
\cline { 2 - 3 } & $\begin{array}{l}\text { Exposed, } \\
\boldsymbol{n}(\%)\end{array}$ & $\begin{array}{l}\text { Unexposed, } \\
\boldsymbol{n}(\%)\end{array}$ & $\begin{array}{l}\text { Total, } \\
\boldsymbol{n}(\%)\end{array}$ \\
\hline $\begin{array}{l}\text { Hypertension }+ \\
\text { myocardial infarction }\end{array}$ & & & \\
$\quad$ Yes & $98(6.5)$ & $37(4.1)$ & $135(5.6)$ \\
No & $1394(93.0)$ & $839(93.4)$ & $2233(93.2)$ \\
Missing information & $7(0.5)$ & $22(2.5)$ & $29(1.2)$ \\
Total & $1499(64.1)$ & $898(37.5)$ & $2397(100.0)$
\end{tabular}

Hypertension +

pneumonia

$\begin{array}{llll}\text { Yes } & 178(11.9) & 80(8.9) & 258(10.8) \\ \text { No } & 792(88.2) & 1311(87.5) & 2103(87.7) \\ \text { Missing information } & 10(2.9) & 26(2.9) & 36(1.5) \\ \text { Total } & 1499(64.1) & 898(37.5) & 2397(100.0)\end{array}$

Pneumonia +

arrhythmia

$\begin{array}{llll}\text { Yes } & 74(4.9) & 52(5.8) & 126(5.2) \\ \text { No } & 1422(94.9) & 831(92.5) & 2253(94.0) \\ \text { Missing information } & 3(0.2) & 15(1.7) & 18(0.8) \\ \text { Total } & 1499(64.1) & 898(37.5) & 2397(100.0)\end{array}$

Pneumonia +

myocardial infarction

$\begin{array}{llll}\text { Yes } & 29(1.9) & 1.7(1.8) & 46(1.9) \\ \text { No } & 1470(98.1) & 867(96.7) & 2337(97.5) \\ \text { Missing information } & - & 14(1.5) & 14(0.6) \\ \text { Total } & 1499(64.1) & 898(37.5) & 2397(100.0)\end{array}$

Exposed $=$ communities located $1-2 \mathrm{~km}$ from mine dumps; Unexposed $=$ communities located $\geq 5 \mathrm{~km}$ from mine dumps.

\section{Multivariate analyses of comorbidity in all 11 study communities}

Crude and adjusted ORs for all risk factors except for the main exposure factor are shown in Tables 5 and 6 . Results from the multiple LRA (Table 7) indicated that living in the exposed communities was significantly associated with asthma + hypertension (OR 1.67; 95\% CI 1.22 - 2.28), asthma + pneumonia (OR 1.86, 95\% CI 1.14 - 3.04), emphysema + arrhythmia (OR 1.38, 95\% CI 1.07 - 1.77), emphysema + myocardial infarction (OR 2.01; 95\% CI 1.73 - 2.54), emphysema + pneumonia (OR 3.36; 95\% CI 1.41 - 7.98), hypertension + myocardial infarction (OR 1.60; 95\% CI $1.04-2.44$ ) and hypertension + pneumonia (OR 1.34; 95\% CI 1.05 - 1.93).

Population group was not associated with any of the health outcomes considered in this study. The study participants in the age groups $65-69$ and $70-84$ years were at an increased likelihood (61.0\%) of having asthma + hypertension. Female participants were at an increased risk of having emphysema + arrhythmia (OR 2.02; 95\% CI 1.10 - 3.72). Participants with primary school as their highest level of education were $49.0 \%$ more likely to have asthma + hypertension. Current smoking and being an ex-smoker significantly increased the likelihood of having asthma + arrhythmia, asthma + emphysema, emphysema + arrhythmia and emphysema + myocardial infarction, and were not associated with asthma + hypertension and asthma + pneumonia. A history of occupational exposure to dust/chemical fumes was significantly associated with asthma + hypertension (OR 1.31; 95\% CI 1.01 - 1.76). Using polluting fuels such as paraffin or gas for cooking/heating in the home had a significant detrimental association with asthma + pneumonia (OR 2.38; 95\% CI 1.08 - 5.23) (Table 6).

No significant effect modification between community type (exposed/unexposed) and other air pollution source variables investigated was observed.

\section{Discussion}

This is the first study to investigate the risk factors associated with comorbidity of respiratory and cardiovascular diseases among elderly people in exposed communities in SA. The results suggest that there was a high prevalence of comorbidity in exposed communities. Living in exposed communities, age, smoking habits, a history of occupational exposure to dust/chemical fumes, and use of gas for cooking/heating in the home were found to be significant risk factors for comorbidity of respiratory and cardiovascular diseases.

Mine dumps are considered to be major sources of wind-blown dust that not only constitutes a nuisance but represents a risk to human health. ${ }^{[2,16,21-25]}$ Size distribution analysis of dust particles from mine dumps has revealed high levels of respirable components. According to previous research done on one of the mine dumps in this study, the ambient concentration of particulate matter with an aerodynamic diameter of $<10 \mu \mathrm{m}\left(\mathrm{PM}_{10}\right)$ greatly exceeded the 24-hour limit set by the SA Department of Environmental Affairs $\left(180 \mu \mathrm{g} / \mathrm{m}^{3}\right){ }^{[2,26]}$ Residential developments are encroaching on the bases of mine dumps ${ }^{[1]}$ and ongoing reclamation of gold from mine dumps observed during the survey increased exposure to particulate matter. Respiratory and cardiovascular diseases were therefore caused or aggravated by exposure to dust from mine dumps.

Ageing is an intricate process associated with an increased risk of cardiovascular and respiratory disease ${ }^{[27-29]}$ as a result of changes in cellular and organ function. ${ }^{[30,31]}$ In this study, an increase in age was not associated with comorbidity of cardiovascular and respiratory diseases. A possible explanation for this finding could be a survivor effect. Contrary to findings reported elsewhere, ${ }^{[32]}$ population group was not associated with the comorbidity outcomes considered in this study. Lower levels of education were also not significantly associated with outcomes of interest in this study, although they are generally known to be linked with lower socioeconomic status and have previously been identified as a risk factor for cardiovascular and respiratory diseases. ${ }^{[33,34]}$ Current and ex-smoking was significantly associated with respiratory and cardiovascular diseases. Ex-smokers were at higher risk than current smokers of having cardiovascular and respiratory disease comorbidity. Having being diagnosed with cardiovascular and or respiratory disease may have been the reason why study participants stopped smoking. Another possibility could have been advice from doctors, which has been shown to contribute to smoking cessation. ${ }^{[35]}$

The cardiovascular and respiratory systems are vulnerable to occupational exposures owing to direct contact with the ambient environment and inhalation of toxic substances. ${ }^{[36,37]}$ Occupational exposure to dust or chemicals was significantly associated with cardiovascular and respiratory diseases. The findings of this study are in agreement with other research in this respect. ${ }^{[38,39]}$ Domestic use of gas and paraffin (kerosene) was significantly associated with cardiovascular and respiratory diseases, possibly caused by the oxides of nitrogen or carbon monoxide generated when gas or paraffin is burned. ${ }^{[40,41]}$ 


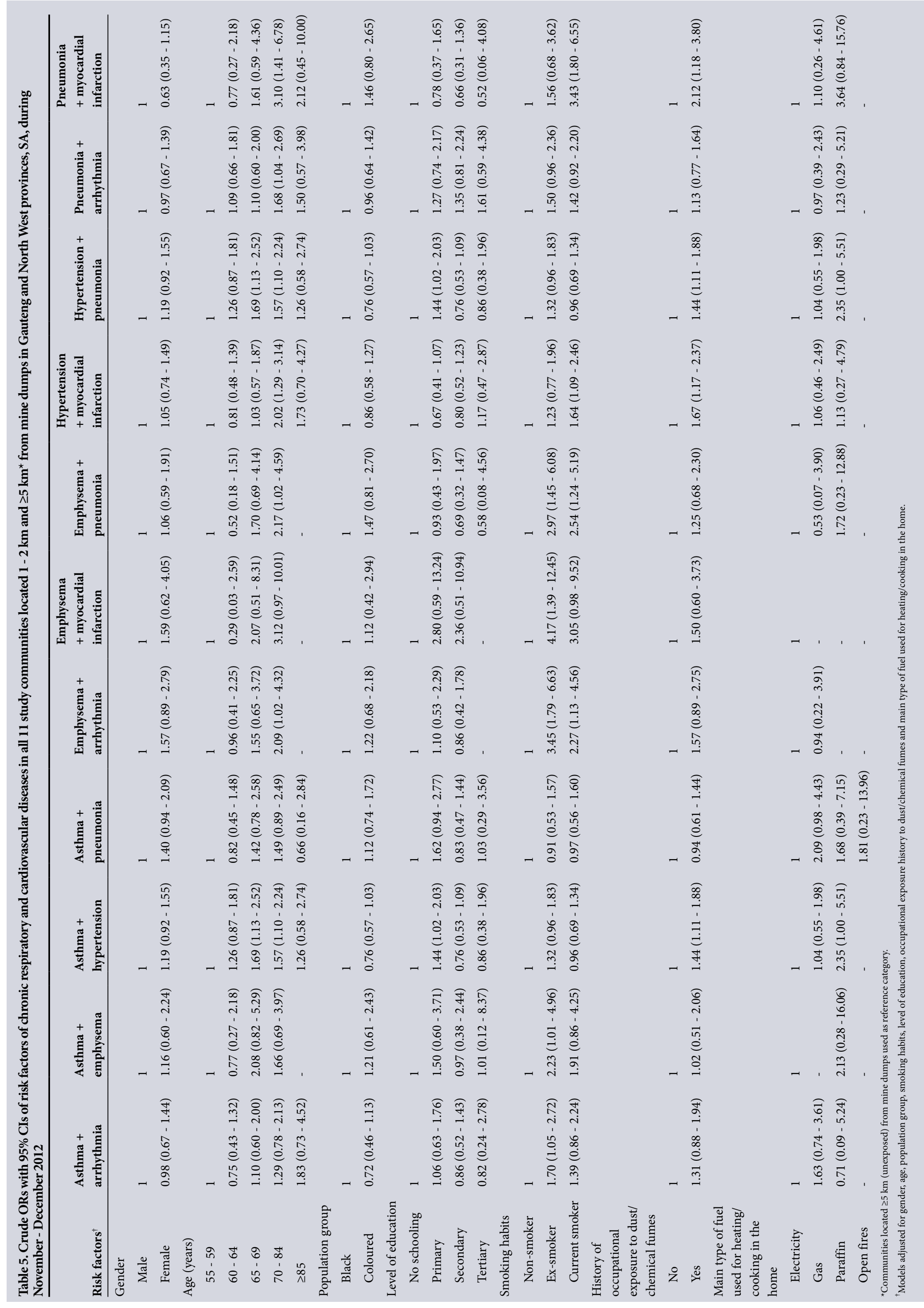




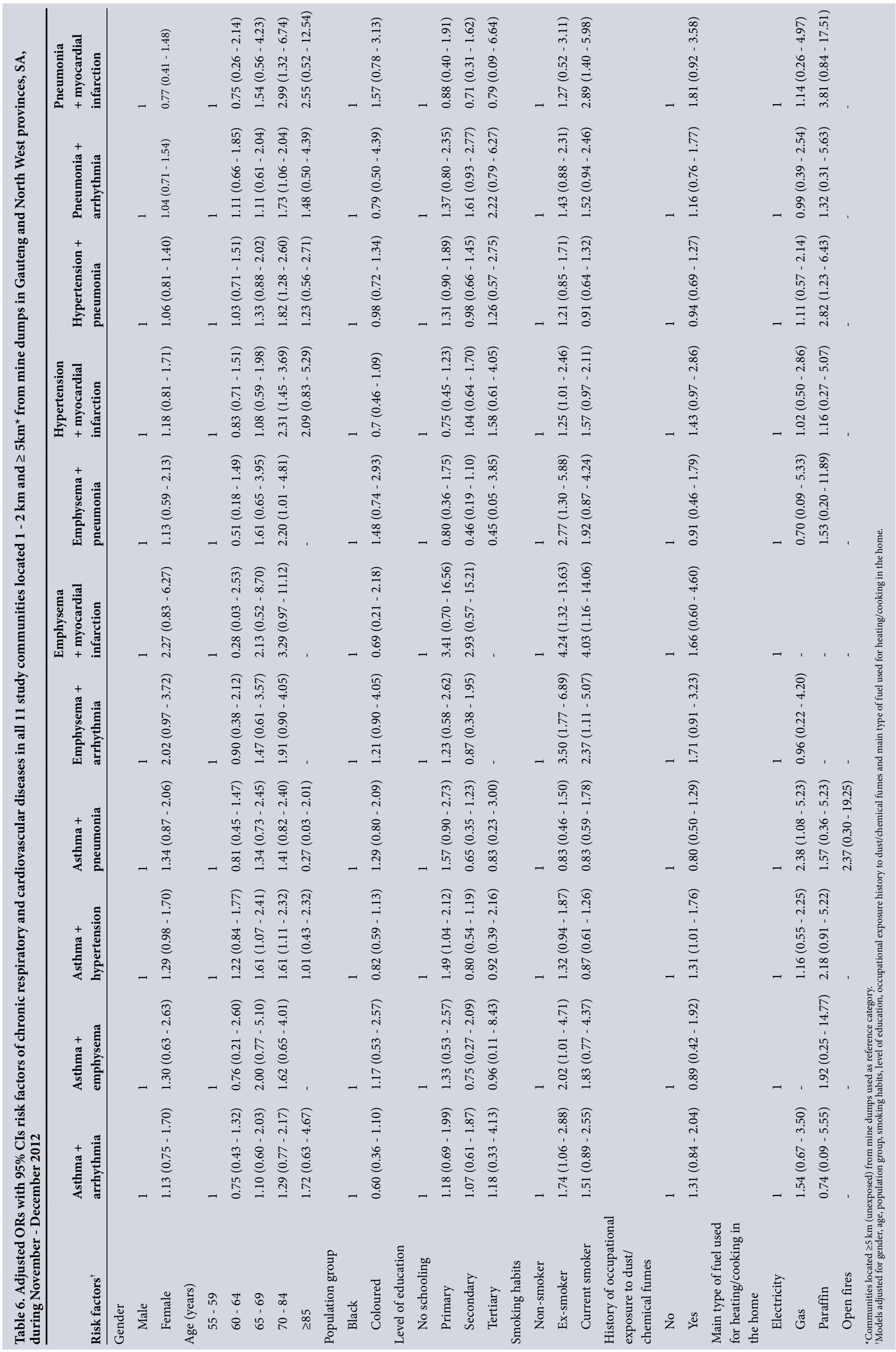


Table 7. Univariate and multivariate analyses of respiratory and cardiovascular diseases comorbidity in all 11 study communities located $1-2 \mathrm{~km}$ and $\geq 5 \mathbf{k m}^{\star}$ from mine dumps in Gauteng and North West provinces, SA, during November - December 2012

\begin{tabular}{|c|c|c|c|c|}
\hline 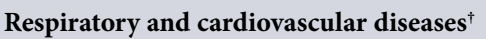 & Crude OR (95\% CI) & $p$-value & Adjusted OR (95\% CI) & $p$-value \\
\hline Asthma + arrhythmia & $0.88(0.59-1.29)$ & 0.506 & $0.82(0.53-1.27)$ & 0.373 \\
\hline Asthma + emphysema & $1.57(0.75-3.27)$ & 0.230 & $1.41(0.64-3.10)$ & 0.390 \\
\hline Asthma + hypertension & $1.77(1.43-2.20)$ & $<0.001$ & $1.67(1.22-2.28)$ & 0.001 \\
\hline Asthma + pneumonia & $1.72(1.12-2.63)$ & 0.013 & $1.86(1.14-3.04)$ & 0.016 \\
\hline Emphysema + arrhythmia & $1.25(1.01-1.58)$ & 0.018 & $1.38(1.07-1.77)$ & 0.014 \\
\hline Emphysema + myocardial infarction & $1.96(1.65-2.32)$ & $<0.001$ & $2.01(1.73-2.54)$ & $<0.001$ \\
\hline Emphysema + pneumonia & $3.31(1.47-7.45)$ & 0.004 & $3.36(1.41-7.98)$ & 0.006 \\
\hline Hypertension + myocardial infarction & $1.59(1.08-2.34)$ & 0.018 & $1.60(1.04-2.44)$ & 0.033 \\
\hline Hypertension + pneumonia & $1.34(1.01-1.78)$ & 0.037 & $1.43(1.05-1.93)$ & 0.022 \\
\hline Pneumonia + arrhythmia & $0.83(0.58-1.19)$ & 0.322 & $0.73(0.48-1.09)$ & 0.130 \\
\hline Pneumonia + myocardial infarction & $1.01(0.55-1.84)$ & 0.984 & $0.77(0.39-1.50)$ & 0.441 \\
\hline
\end{tabular}

\section{Study limitations}

Some limitations and advantages of this study have been published previously. ${ }^{[6]}$ The study has additional limitations inherent to crosssectional epidemiological study designs: $(i)$ it cannot provide any evidence of causality; (ii) no quantitative air pollution exposure assessment was conducted; and (iii) it relied on doctor-diagnosed respiratory and cardiovascular diseases, which, although specific, can underestimate disease prevalence. It is therefore assumed that several individuals with respiratory and cardiovascular diseases were missed as a result of restrictive definitions employed in this study or poor access to healthcare facilities. ${ }^{[42]}$ The possibility of estimating falsely low prevalence figures cannot be ignored. However, the observed high prevalence of respiratory and cardiovascular diseases in exposed communities cannot be attributed only to the strict definition used, but is also likely to be due to a complex interaction of social, economic, and behavioural factors such as air pollution, undernutrition, poor access to healthcare or lifestyle behaviours. ${ }^{[43,44]}$ Further limitations are that: (iv) interviewer error may have occurred during translation of the questions into the local language during interviews with study participants who did not understand English; $(v)$ unwillingness of the respondents to provide honest answers, or their giving socially desirable responses, should be taken into account in the interpretation of results; and $(v i)$ no data were collected on possible reasons for declining to take part - the differential participation rate between exposed and unexposed communities is of concern and may well have introduced response bias, which is likely to overestimate the prevalence estimates derived and bias the association in either direction; and (vii) data on how access to healthcare varied between exposed and unexposed communities were not collected. Interviewing $10 \%$ of the study respondents twice resulted in $96 \%$ repeatability.

\section{Conclusion}

The findings of this study suggest a high prevalence of respiratory and cardiovascular diseases, with detrimental associations observed between comorbidity of the health outcomes and proximity to mine dumps, among the elderly in SA. The significant risk factors were proximity to mine dumps, age group, occupational exposure history to dust/chemical fumes, and main type of fuel used for heating/ cooking in the home.

Acknowledgments. We thank everybody who participated in the questionnaire interviews, Mr Moses Kebalepile and all the fieldworkers who assisted in data collection, the data technicians for the data capturing, and Statistics South Africa for providing the population sizes of elderly people in each study community. The study was funded by the Mine Health Safety Council, the National Research Fund - Deutscher Akademischer Austausch Dienst and the University of Pretoria.

\section{References}

1. Oguntoke O, Ojelede ME, Annegarn HJ. Frequency of mine dust episodes and the influence of meteorological parameters on the Witwatersrand area, South Africa. Int J Atmos Sci 2013;2013(1):110. [http://dx.doi.org/10.1155/2013/128463]

2. Ojelede ME, Annegarn HJ, Kneen MA. Evaluation of aeolian emissions from gold mine tailings on the Witwatersrand. Aeolian Res 2012:3(4):477-486. [http://dx.doi.org/10.1016/j.aeolia.2011.03.010]

Moreno ME Acosta-Savede LC Meza-Figueroa D, et Bl Biomonitoing of meta in children living in Moreno ME, Acosta-Saavedra LC, Meza-Figueroa D, et al. Biomonitoring of metal in children living in a mine tailings zone in Southern Mexico: A pilot study. Int J Hyg Environ Health 2010; 213(4):252-258.
[http://dx.doi.org/10.1016/j.ijheh.2010.03.005] (hti

4. Saunders JR, Knopper LD, Yagminas A, Koch I, Reimer KJ. Use of biomarkers to show sub-cellula effects in meadow voles (Microtus pennsylvanicus) living on an abandoned gold mine site. Sci Total Environ 2009;407(21):5548-5554. [http://dx.doi.org/10.1016/j.scitotenv.2009.07.026]

5. Bussières D, Ayotte P, Levallois P, et al. Exposure of a Cree population living near mine tailings in northern Quebec (Canada) to metals and metalloids. Arch Environ Health 2004;59(12):732-741. [http://dx.doi.org/10.1080/00039890409602960]

6. Nkosi V, Wichmann J, Voyi K. Chronic respiratory disease among the elderly in South Africa: Any association with proximity to mine dumps? Environ Health 2015;14(33):1-8. [http://dx.doi. org/10.1186/s12940-015-0018-7

Nkosi V, Wichmann J, Voyi K. Mine dumps, wheeze, asthma and rhino-conjunctivitis among adolescents in South Africa: Any association? Int J Environ Health Res 2015;25(6):583-600. [http:// dx.doi.org/10.1080/09603123.2014.989493]

8. Wright CY, Matooane M, Oosthuizen MA, Phala N. Risk perceptions of dust and its impacts among communities living in a mining area of the Witwatersrand, South Africa. Clean Air J 2014;24(1):22-27.

Dominici F, Peng RD, Bell ML, et al. Fine particulate air pollution and hospital admission for cardiovascular and respiratory diseases. JAMA 2006;295(10):1127-1134. [http://dx.doi.org/10.1001/
(a) cardiovascular and

jama.295.10.1127]
10. Sacks JD, Stanek LW, Luben TJ, et al. Particulate matter-induced health effects: Who is susceptible? Sacks JD, Stanek LW, Luben TJ, et al. Particulate matter-induced health effects: Who is
Environ Health Perspect 2011;119(4):446-454. [http://dx.doi.org/10.1289/ehp.1002255]

11. Lee JT, Son JY, Cho YS. The adverse effects of fine particle air pollution on respiratory function in the elderly. Sci Total Environ 2007;385(1-3):28-36. [http://dx.doi.org/10.1016/j.scitotenv.2007.07.005] 2. Mills NL, Donaldson K, Hadoke PW, et al. Adverse cardiovascular effects of air pollution. Nat Clin Pract Cardiovasc Med 2009;6(1):36-44. [http://dx.doi.org/10.1038/ncpcardio1399]

3. Pope CA, Burnett RT, Thurston GD, et al. Cardiovascular mortality and long-term exposure to particulate air pollution: Epidemiological evidence of general pathophysiological pathways of disease. Circulation 2004;109(1):71-77. [http://dx.doi.org/10.1161/01.CIR.0000108927.80044.7F]

14. Simkhovich B. Air pollution and cardiovascular injury: Epidemiology, toxicology, and mechanisms. J Am Coll Cardiol 2008;52(9):719-726. [http://dx.doi.org/10.1016/j.jacc.2008.05.029]

15. Bentayeb M, Simoni M, Baiz N. Adverse respiratory effects of outdoor air pollution in the elderly. Int $J$ Bentayeb M, Simoni M, Baiz N. Adverse respiratory effects of outdoor air pollutio
Tuberc Lung Dis 2012;16(9):1149-1161. [http://dx.doi.org/10.5588/ijtld.11.0666]

Tuberc Lung Dis 2012;16(9):1149-1161. [http://dx.doi.org/10.5588/ijtld.11.0666]
16. Mayan ON, Gomes MJ, Henriques A, Silva S, Begonha A. Health survey among people living near Mayan ON, Gomes MJ, Henriques A, Silva S, Begonha A. Health survey among people living near
an abandoned mine. A case study: Jales mine, Portugal. Environ Monit Assess 2006;123(1-3):31-40. an abandoned mine. A case study: Jales mine,
[http://dx.doi.org/10.1007/s10661-005-9078-4]

17. Fenn B, Morris SS, Black RE. Comorbidity in childhood in northern Ghana: Magnitude, associated factors and impact on mortality. Int J Epidemiol 2005;34(2):368-375. [http://dx.doi.org/10.1093/ije/dyh335]

18. Comstock GW, Tockman MS, Helsing KJ, Hennesy KM. Standardized respiratory questionnaires Comparison of the old with the new. Am Rev Respir Dis 1979;119(1):45-53.

19. Groenwold RHH, Klungel OH. Selection of confounding variables should not be based on observed associations with exposure. Eur J Epidemiol 2011;26(1)589-593. [http://dx.doi.org/10.1007/s10654011-9606-1]

20. Gortmaker SL, Hosmer DW, Lemeshow S. Applied Logistic Regression Analysis. 2nd ed. New York: John Wiley \& Sons, 1994:159.

21. Meck M, Love D, Mapani B. Zimbabwean mine dumps and their impacts on river water quality a reconnaissance study. Phys Chem Earth 2006;31(15-16):797-803. [http://dx.doi.org/10.1016/j. pce.2006.08.029]

22. Jonnalagadda SB, Nenzou G. Studies on arsenic rich mine dumps: II. The heavy element uptake by vegetation. J Environ Sci Health 1997;32(2):455-464. [http://dx.doi.org/10.1080/10934529709376554] 
23. Jonnalagadda SB, Nenzou G. Studies on arsenic rich mine dumps: III. Effect on the river water. J Environ Sci Health 1996;31(10):2547-2555. [http://dx.doi.org/10.1080/10934529609376509]

24. Chang P, Kim JY, Kim KW. Concentrations of arsenic and heavy metals in vegetation at two abandoned mine tailings in South Korea. Environ Geochem Health 2005;27(2):109-119. [http://dx.doi.org/10.1007/s10653-005-0130-7]

25. Kon LC, Durucan S, Korre A. The development and application of a wind erosion model for the assessment of fugitive dust emissions from mine tailings dumps. International Journal of Mining Reclamation and Environment 2007;21(3):198-218. [http://dx.doi.org/10.1080/17480930701365547] 26. National Environmental Management. Air Quality Act 39 of 2004. Government Notice Gazette 2005, No. 28016. http://www.saflii.org/za/legis/consol_act/nemaqa2004454 (accessed 21 October 2015).

27. Lakatta EG. Age-associated cardiovascular changes in health: Impact on cardiovascular disease in older persons. Heart Fail Rev 2002;7(1):29-49. [http://dx.doi.org/10.1023/A:1013797722156, http:// dx.doi.org/10.1023/A:1013708104410

28. Deveci F, Deveci SE, Türkoğlu S, et al. The prevalence of chronic obstructive pulmonary disease in Elazig. Eastern Turkey Eur I Intern Med 2011;22(2):172-176. [http://dx.doiorg/10.1016/j. ejim.2010.12.014]

29. Brashier B, Londhe J, Madas S, Vincent V, Salvi S. Prevalence of self-reported respiratory symptoms, asthma and chronic bronchitis in slum area of a rapidly developing Indian city. Open J Respir Dis 2012, 2(3):73-81. [http://dx.doi.org/10.4236/ojrd.2012.23011]

30. Dimmeler S, Nicotera P. MicroRNAs in age-related diseases. EMBO Mol Med 2013:5(2)180-190. [http://dx.doi.org/10.1002/emmm.201201986]

31. Sharma G, Goodwin J. Effect of aging on respiratory system physiology and immunology. Clin Interv Aging 2006;1(3):253-260. [http://dx.doi.org/10.2147/ciia.2006.1.3.253]

32. Phaswana-Mafuya N, Peltzer K, Chirinda W, et al. Self-reported prevalence of chronic noncommunicable diseases and associated factors among older adults in South Africa. Glob Health Action 2013;6(20936):1-7. [http://dx.doi.org/10.3402/gha.v6i0.20936]

33. Damiani G, Federico B, Bianchi CBNA. Socio-economic status and prevention of cardiovascular disease in Italy: Evidence from a national health survey. Eur J Publ Health 2011;21(5)591-596. [http:// dx.doi.org/10.1093/eurpub/ckq075
34. Kanervisto M, Vasankari T, Laitinen T, et al. Low socioeconomic status is associated with chronic obstructive airway diseases. Respir Med 2011;105(8):1140-1146. [http://dx.doi.org/10.1016/j.rmed.2011.03.008]

35. Research Committee of the British Thoracic Society. Smoking cessation in patients: Two further studies by the British Thoracic Society. Thorax 1990;45(11):835-840. [http://dx.doi.org/10.1136/thx.45.11.835] 36. Upadhyay S, Ganguly K, Stoeger T, et al. Cardiovascular and inflammatory effects of intratracheally instilled ambient dust from Augsburg, Germany, in spontaneously hypertensive rats (SHRs). Part Fibre Toxicol 2010;7(27):1-20. [http://dx.doi.org/10.1186/1743-8977-7-27]

37. Balmes JR. Occupational respiratory diseases. Prim Care 2000;27(4):1009-1038. [http://dx.doi. org/10.1016/S0095-4543(05)70187-1]

38. Ibfelt E, Bonde JP, Hansen J. Exposure to metal welding fume particles and risk for cardiovascular disease in Denmark: A prospective cohort study. Occup Environ Med 2010;67(11):772-777. [http:// dx.doi.org/10.1136/oem.2009.051086]

39. Blanc PD, Iribarren C, Trupin L, et al. Occupational exposures and the risk of COPD: Dusty trades revisited. Thorax 2009;64(1):6-12. [http://dx.doi.org/10.1136/thx.2008.099390]

40. Jarvis D, Chinn S, Luczynska C, Burney P. Association of respiratory symptoms and lung function in young adults with use of domestic gas appliances. Lancet 1996;347(8999):426-431. [http://dx.doi. org/10.1016/S0140-6736(96)90009-4]

41. Dennekamp M, Howarth S, Dick CA, et al. Ultrafine particles and nitrogen oxides generated by gas and electric cooking. Occup Environ Med 2001;58(8):511-516. [http://dx.doi.org/10.1136/oem.58.8.511]

42. Harris B, Goudge J, Ataguba JE. Inequities in access to health care in South Africa. J Public Health Policy 2011;32(Suppl 1):S102-S123. [http://dx.doi.org/10.1057/jphp.2011.35]

43. Aggarwal AN, Chaudhry K, Chhabra SK. Prevalence and risk factors for bronchial asthma in Indian adults: A multicentre study. Indian J Chest Dis Allied Sci 2006;48(1):13-22.

44. Agarwal S, Srivastava A, Kumar S. Urban health in developing countries. In: Gibbons MC, Bali R, Wickramasinghe N, eds. Perspectives of Knowledge Management in Urban Health. Springer, 2010:6194. [http://dx.doi.org/10.1007/978-1-4419-5644-6_5

Accepted 21 October 2015 